\title{
An efficient protocol for genomic DNA extraction from formalin-fixed paraffin- embedded tissues
}

\author{
Sara Santos a , Daniela Sá ${ }^{\mathrm{a}}$, Estela Bastos ${ }^{\mathrm{a}}$, Henrique Guedes-Pinto ${ }^{\mathrm{a}}$, Ivo Gut ${ }^{\mathrm{b}}$, Fátima Gärtner ${ }^{\mathrm{c}, \mathrm{d}}$, Raquel Chaves ${ }^{\mathrm{a}, *}$

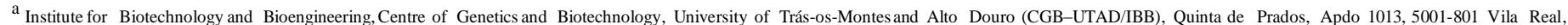 \\ Portugal \\ b CEA/IG - CentreNationalde Génotypage, 2 rue Gaston Crémieux, CP 5721, 91057 Evry Cedex, France \\ ${ }^{\mathrm{c}}$ Instituto de Ciências Biomédicas de Abel Salazar (ICBAS), University of Porto, Largo Prof. Abel Salazar, 2, 4099-003 Porto, Portugal \\ ${ }^{\mathrm{d}}$ Institute of Molecular Pathology and Immunology of the University of Porto (IPATIMUP), Rua Dr. Roberto Frias, s/n, 4200-465 Porto, Portugal
}

* Corresponding author. Tel.: +351 259 350841; fax: +351 259 350572. E-mail address: rchaves@utad.pt (R. Chaves).

\begin{abstract}
Formalin-fixed paraffin-embedded tissues (FFPET) represent the largest source of archival biological material available for genomic studies. In this work we present an advanced protocol for extraction of high quality DNA from FFPET that can be applied in several molecular studies. Although cat mammary tumours (CMT) are the third most frequent tumour in cats the recovery of significant number of samples for molecular studies are in some way restricted to FFPET samples. We were able to obtain high quality DNA from FFPET of thirty six CMT that were subjected to prefixation and fixation processes routinely used in the veterinary hospitals. The quality of DNA obtained was tested by PCR amplification using six sets of primers that amplify single-copy fragments. The DNA fragments obtained were further sequenced. This protocol was able to provide FFPET gDNA that can be amplified and sequenced for larger fragments up to $1182 \mathrm{bp}$.
\end{abstract}

Keywords: DNA extraction, Formalin-fixed paraffin-embedded tissues, Cat mammary tumours, PCR amplification, Sequencing

\section{Introduction}

With growing interest in the genetic basis of diseases the amount of genomic DNA available from biological samples may limit the practicality of genomic analysis (Aviel-Ronen et al.,2006; Gilbert et al., 2007b). Formalin-fixed paraffin-embedded tissues (FFPET) have been used for decades and represent the largest source of archival biological material available for genomic studies (Aviel-Ronen et al., 2006). In some cases, like rare diseases, the FFPET represents the ultimate DNA resource available for genetic analysis that otherwise would be unfeasible (Gilbert et al., 2007a).

Previous studies using FFPET of cat mammary tumours (CMT) described molecular changes in oncogenes such as Her2/neu (De Maria et al., 2005; Winston et al., 2005; Morris et al., 2008) or tumour suppressor genes such as p53 (Murakami et al., 2000; Nasir et al., 2000; Morris et al., 2008) by immunohistochemical studies. The detection of mutations in the p53 tumour suppressor gene was previously reported in CMT but in fresh tissues (Mayr et al., 1998). In fact, the nuclear DNA extraction and analysis of cat FFPET has only been reported regarding the amplification of a $108 \mathrm{bp}$ single copy fragment from p53 gene as a positive control for gDNA extraction with a commercial protocol (Kidney et al., 2002). An interesting opportunity for comparative oncology has been recognized in naturally occurring tumours in domestic animals (MacEwen, 1990; Vail and MacEwen, 2000) and, more specifically, CMT may be considered a good model for their human counterpart (MacEwen, 1990; Hansen and Khanna, 2004; Zappulli et al., 2005).

The use of nucleic acids extracted from FFPET in procedures of molecular genetics is highly dependent on its quality and quantity. Different authors state that a suitable DNA extraction method from FFPET is essential and needs to be chosen in relation to specific endpoints of a precise investigation; for instance, the increased length of amplicon or the increase of effective amplifiable copy number (Wang et al., 1996; Poljak et al., 2000; Gilbert et al.,2007b). Therefore diverse nucleic acid extraction methods already described from FFPET, enable the use of DNA extracted for specific approaches: nested PCR-SSCP assay (Wang et al., 1996), RAPDPCR (Jacobs et al., 2007), real-time quantitative PCR (Gjerdrum et al.,2004), Southern blot hybridisation (e.g. Dubeau et al., 1986; Jackson et al., 1990; Rogers et al., 1990), flow cytometry (Leers et al.,1999), microarray comparative genomic hybridization (Vékony et al., 2007) and SNP BeadArrays (Oosting et al., 2007).

It is well known that the quality and quantity of nucleic acid extracted are highly dependent on a large number of parameters concerning all the procedures that involved the FFPET handling (before and after the DNA extraction itself) (Greer et al., 1991; Romero et al., 1997; Benavides et al., 2006; Gilbert et al., 2007a). Sample manipulation (i.e. type and amount of tissue, and its preservation before fixation), fixation methodology (i.e. which fixative was chosen, fixative $\mathrm{pH}$, and temperature and time of fixation) as well as post-fixation features (i.e. temperature and period of storage) are considered the most important nucleic acid preextraction parameters (Greer et al., 1991; Miething et al., 2006; Wang et al., 1996; Poljak et al., 2000). In order to optimize the quality and quantity of the nucleic acid extraction, pre-extraction procedures to remove paraffin from fixed tissues (e.g. use of Xylene and ethanol washes) is believed to be important; otherwise it leads to poor quality of the samples and inhibition of subsequent PCR reactions. However, a growing number of authors do not employ specific protocols to remove the paraffin (e.g. Stanta and Schneider, 1991; Wu et al.,2002; Shi et al., 2004).

In the wide variety of methods for DNA extraction from FFPET, the majority was applied to collections of human samples, fixed with formalin (the fixative generally used in histopathological practice) 
(Gjerdrum et al., 2004). In veterinary clinics the procedures used are essentially the same. In fact, the fixative formalin is one of the main problems with respect to the quality of DNA extracted from FFPET, namely the increased formalin $\mathrm{pH}$ (Poljak et al., 2000). Moreover, formaldehyde $(\mathrm{HCHO})$ is the main constituent of formalin that is responsible for the cross-linkage between proteins and DNA or RNA, which in turn could be limiting for further use of the nucleic acids (e.g. Zsikla et al., 2004; Moller et al., 1977). Finally, one of the recent methods described to remove formaldehyde from the specimens is the application of graded ethanol washes followed by a drying critical point (Fang et al., 2002). This method is presented as increasing both DNA yield, and maximum size of PCR amplifiable fragment. Unfortunately, this study involved only eight FFPET samples and there was a lack of subsequent interest in this method (Gilbert et al., 2007a). In DNA extraction methods itself it is important to consider some factors as the composition of the extraction buffer (with or without incorporation of proteinase-K), and time and temperature of the digestion step (Gilbert et al., 2007a).

In this work we present an advanced protocol for extraction of high quality DNA from FFPET that can be applied in several molecular studies. Although cat mammary tumours are the third most frequent tumour in cats (Zappulli et al., 2005; Seixas et al., 2008) the recovery of significant number of samples for molecular studies are in some way restricted to FFPET collected during a long period of time. Here, we were able to obtain high quality DNA from FFPET of thirty six cat mammary tumours that were subjected to pre-fixation and fixation processes routinely used in the veterinary hospitals. The quality of DNA obtained was tested by PCR amplification using six sets of primers that amplify single-copy fragments. The DNA fragments obtained were further sequenced. The protocol described here was able to provide FFPET gDNA that can be amplified and sequenced for larger fragments up to $1182 \mathrm{bp}$.

\section{Materials and methods}

Thirty six cat mammary tumours FFPE samples were obtained from two histopathology laboratories from the University of Porto: Institute of Molecular Pathology and Immunology of the University of Porto (IPATIMUP) and Instituto de Ciências Biomédicas de Abel Salazar (ICBAS). All samples were collected and formalin fixed in various veterinary hospitals and the following routine paraffin wax embedding procedures were undertaken in the histopathology laboratories. Frozen samples $(n=30)$ from cat mammary tumours and normal muscle and skin tissues were used as controls and were kindly provide by the Trás-os-Montes Veterinary Hospital and ICBAS. All tissues were evaluated by pathology procedures; the cat mammary tumour biopsies represent histological heterogeneous samples. All biopsies and necropsies were carried out between the years of 2005 to 2007 .

\subsection{DNA Extraction from FFPE tissues}

The DNA extraction from FFPE tissues were performed using the Automatic Nucleic Acid Isolation System (QuickGene 800, Fujifilm Life Science). The system uses a porous ultra thin membrane and an automatically pressurizing unit that promote binding, washing and elution steps at low pressure. In order to apply this system to the isolation of genomic DNA from FFPET, several modifications were carried out: melting and removal of the paraffin; time and temperature of the lyses procedure; and the elution time. All other steps of the procedure in the DNA extraction protocol were executed according to the one described by the manufacturer "Quick- Gene DNA Tissue Kit S" (Fujifilm Life Science).

Tissue sections were observed by light microscopy to determine the location of tumour cells. After slide observation, the paraffin wax blocks were sliced with a blade in the area of interest. DNA was extracted from approximately 5 to $20 \mathrm{mg}$ fragments of paraffinembedded tissue samples, cut in small sections and collected in a 0.5 $\mathrm{ml}$ microcentrifuge tube.

The paraffin of each sample was melted in $50 \mathrm{ll}$ of a Tween 20 solution (0.5\% Tween 20, 1 mM EDTA, $50 \mathrm{mM}$ Tris- $\mathrm{HCl} \mathrm{pH} 8.5)$ at $95 \mathrm{C}$ for $10 \mathrm{~min}$ followed by a second round of incubation at $65 \mathrm{C}$ for $10 \mathrm{~min}$. The tissue digestion was done with proteinase K (MDT with EDT reagents in the original protocol from QuickGene DNA Tissue Kit S, Fujifilm Life Science) at $65 \mathrm{C}$ in an overnight water bath with agitation as described by manufacture. The samples were then centrifuged at $16000 \mathrm{rcf}$ for $5 \mathrm{~min}$, at $0 \mathrm{C}$. At this time it is possible to observe a paraffin layer in the top of the digestion solution. In order to eliminate all the paraffin it is advisable to remove the paraffin layer using a glass Pasteur pipette closed in the tip. An additional proteinase $\mathrm{K}$ digestion at $65 \mathrm{C}$, during $1 \mathrm{~h}$, was performed. Finally, an extra step for the elimination of the residual paraffin was added and this specific procedure was evaluated in the general performance of the protocol regarding integrity, quantity and quality of the gDNA obtained. Therefore, all samples were centrifuged at $15000 \mathrm{rcf}$ for 35 min at $4 \mathrm{C}$ and the supernatant was collected avoiding the paraffin residues.

As described by the manufacturer, cell lyses was performed by incubating the samples with the cell lyses buffer (LDT in the protocol from QuickGene DNA Tissue Kit S, Fujifilm Life Science) during 10 min at $70 \mathrm{C}$ and DNA was precipitated by adding $240 \mathrm{ll}$ of ethanol.

At this time, all the lysates were transferred to the purification columns of the automatic nucleic-acid isolation system Quick- Gene800. The program "DNA Tissue" was used with the time of elution set to its maximum value. The protocol was optimized for the standardized final volume of $100 \mathrm{ll}$ (the elution buffer used was the one furnished by the manufacturer).

The use of DNA samples obtained from FFPE tissues on subsequent procedures is depends on the quality of the DNA and its storage. The DNA samples should be stored at $20 \mathrm{C}$ for longer storage periods, however better results were achieved when extracts were not frozen.

\subsection{DNA Extraction from frozen tissue samples}

The isolation of genomic DNA from frozen tissues was performed with the QuickGene DNA Tissue Kit S (Fujifilm Life Science) following the procedures described by the manufacturer.

\subsection{Evaluation of gDNA from paraffin-embedded tissue}

In order to analyse the integrity of the genomic DNA extracted all samples were subjected to a $1 \%$ agarose gel electrophoresis. The quantity and quality of the DNA extracted was measured in a NanoDrop ND-1000 spectrophotometer (NanoDrop Technologies, Wilmington USA). The statistical analysis of the values regarding the quantity of the gDNA obtained was done with the "StatsDirect" program. A Kruskal-Wallis test was applied to the gDNA quantity obtained for variance evaluation of independent samples as described by Ribeiro et al. (2004). 
As described by different authors, the quality and total DNA contents provided by NanoDrop are inaccurate in representing the quantity of DNA that is efficiently amplifiable by PCR (Gilbert et al., 2007b). In order to analyse the quality of amplifiable DNA, all thirtysix samples were PCR amplified using six sets of primers that amplify single-copy fragments for three different genes of varying length: 343 bp and 1182 bp (ERBB2); 355 bp and 590 bp (p53); 201 $\mathrm{bp}$ and $316 \mathrm{bp}$ (Twist1). The primer sets used were selected from CMT projects ongoing in our lab. In order to optimize the PCR conditions, the primers were tested in DNA extracted from cat normal skin or muscle and mammary frozen tissues.

For PCR amplification, 10-15 IL (representing $500 \mathrm{ng}$ ) of purified FFPET gDNA was added to a final volume of $30 \mathrm{lL}$ and the PCR reaction mixtures contained $3 \mathrm{U}$ of Taq DNA polymerase (Fermentas Life Science). The amplification reactions were performed under standard conditions. Amplicons were analysed on 1\% agarose gels stained with ethidium bromide and visualized with an ultraviolet transilluminator UviDoc.

\subsubsection{Sequencing of DNA fragments}

To analyse the quality of the amplifiable DNA from FFPET, the fragments obtained were further sequenced in both directions. The sequencing reactions were analysed comparing the results from FFPET gDNA with the ones obtained with gDNA extracted from frozen tissues.

\section{Results}

\subsection{Evaluation of the gDNA integrity by agarose gel electrophoresis}

The DNA extraction protocol established in the present work uses an automatic nuclei-acid isolation system: the QuickGene-800 (Fujifilm Life Technologies). The protocol of this system was adapted to the DNA extraction from FFPET samples. Several modifications were done in order to obtain the maximum gDNA yield, and simultaneously attain high quality gDNA that would work in subsequent applications as PCR, sequencing, etc. One of the most important improvements that were done in the gDNA extraction protocol was the inclusion of an additional step to remove the paraffin (cf. Material and Methods). In fact, during the various steps of the protocol optimization we realized that the paraffin is never completely eliminated. After the tissue digestion it is still observable a paraffin layer in the top of the solution. In order to evaluate the inclusion of this additional step in the protocol we performed gDNA extractions with and without this variation, and both protocol variants were analysed.

The gDNA extraction from FFPET (both protocol variants) was first analysed by agarose gel electrophoresis in order to evaluate the integrity of the gDNA obtained. It was possible to extract gDNA from all the thirty six cat mammary tumours FFPET. The presence of gDNA fragmentation can be observed in Fig 1a, but was potentially reduced with the introduction of the additional procedure to remove the residual paraffin (Fig 1b). In Fig 1b it is also important to observe the discrete gDNA band of high molecular weight.

\subsection{Evaluation of the gDNA quantity and quality by NanoDrop}

The concentration of the gDNA extracted from FFPET was quantified using the NanoDrop ND-1000 (NanoDrop Technologies) equipment. The quantity of the gDNA obtained in the extraction method presented in this work was determined and the data was analysed with the StatsDirect program. In table 1 it is possible to analyse the gDNA extractions without (protocol variant A) and with (protocol variant B) the inclusion of an additional step to remove the residual paraffin. In protocol variant B the mean value of all DNA samples was $262.6 \mathrm{ng} / \mathrm{ll}$ comparing to the variant A (166.1 ng/ll).

The pairwise comparisons with Kruskal-Wallis test (cf. Table 1), demonstrated the existence of significant differences between both protocol variants, confirming that the elimination of the residual paraffin is important as the concentration of the gDNA obtained is higher (for the same initial quantities of tissue used and elution volumes).

The quantity of gDNA obtained was also analysed with regard to the quantity of tissue used (Fig 2). As can be observed in Fig 2, the data demonstrates that the total gDNA yield is optimal when $5-10 \mathrm{mg}$ of tissue are used, being significantly reduced in extractions using higher amounts of original samples. The maximum DNA yield (8390 $\mathrm{ng} / \mathrm{mg}$ ) was obtained for $8.3 \mathrm{mg}$ of FFPET. As FFPET samples are extremely precious and represent unique collections of biological material it is essential to optimize the initial amount of FFPET to be used. The highest yields of gDNA were achieved for reduced amounts used of FFPET samples. This represents a strong feature of this protocol.

The quality of the isolated genomic DNA was estimated in terms of its contamination with proteins or RNA (A260/A280), and chaotropic salt value (A260/A230) using the NanoDrop ND-1000 system (NanoDrop Technologies). According to the NanoDrop standards the A260/A280 ratio is acceptable between 1.8 and 2.0 and is optimal around 1.8. With this protocol $90.5 \%$ (81\% in protocol variant A and $100 \%$ in protocol variant B) of the samples presented A260/A280 ratio values between 1.8 and 2.07. Only the gDNA samples obtained with protocol variant A (19\% of the samples) presented A260/A280 ratios below 1.8 indicating the presence of contaminants such as protein that absorbs strongly at or near $280 \mathrm{~nm}$ (Fig 3). The A260/ A230 ratio was in the optimal range (1.8-2.2) for $64 \%$ of the samples (47\% in protocol variant $A$ and $81 \%$ in protocol variant $\mathrm{B}$ ). The gDNA obtained, mainly with protocol variant $\mathrm{B}$, revealed to be of high quality demonstrating minor levels of contamination with RNA or purification reagents.

\subsection{Evaluation of the gDNA isolated in subsequent applications: PCR and sequencing reactions}

The gDNA obtained with the presented methodology was of highquality regarding all standards employed. Nevertheless, we analyse the quality of DNA in terms of its success in PCR amplification of single copy fragments of different sizes and also in sequencing procedures.

PCR conditions were optimized in gDNA samples obtained from frozen tissue (examples in Fig 4a for DNA fragments from Twist1 gene). Then, we used the thirty six gDNA samples from FFPET and amplified three different single copy genes (i.e. ERBB2, p53 and Twist1) of several length: 343 bp and 1182 bp (ERBB2); 355 bp and 590 bp (p53); 201 bp and 316 bp (Twist1) (cf. Fig 4b-d). In Table 2 we present the success of the PCR amplification. It is important to note that this protocol allows the amplification and sequencing of large single copy fragments (e.g. 1182 bp). The PCR amplification and sequencing of various single copy fragments of three different genes, matching to different regions of the genome, is elucidative of the quality of the gDNA obtained from FFPET. 


\section{Discussion}

Formalin-fixed paraffin-embedded tissues (FFPET) represent the largest source of archived biological material for genomic studies (Aviel-Ronen et al., 2006), and in several cases the only DNA resource available. Therefore it is very important to have protocols for gDNA extraction from FFPET efficient and reproducible, and simultaneously yielding gDNA of high molecular weight with low levels of fragmentation and with high quality. The protocol that we presented here satisfies these features. We also demonstrated that the gDNA obtained was efficiently used in PCR and sequencing reactions.

It was possible to extract gDNA from all thirty six cat mammary tumour FFPET with high molecular weight gDNA and low levels of gDNA fragmentation (Fig 1). The removal of the residual paraffin proves to be an important step to improve DNA yield (Table 1), reduce DNA fragmentation (Fig 1) and results in gDNA of high quality (Fig 3). The maximum DNA yield was optimized in a range of 5-10 mg of FFPET (Fig 2), suggesting that this protocol is indicated when reduced quantities of initial tissue are available.

The evaluation of the gDNA isolated in subsequent applications such as PCR and sequencing reactions confirmed the potential of the protocol presented (Fig 4 and Table 2). We used all the thirty six gDNA samples obtained from FFPET material and amplified three different single copy genes (i.e. ERBB2, p53 and Twist1) of several length: 343 bp and 1182 bp (ERBB2); 355 bp and 590 bp (p53);

201 bp and 316 bp (Twist1) (cf. Fig 4b-d). Table 2 summarizes the results of the PCR amplification reactions and the efficiency of the sequencing procedures. Only the DNA fragments from the ERBB2 gene showed some failure (for up to $40 \%$ of the samples) in its amplification reactions. Nevertheless, one of these fragments has a length of $1182 \mathrm{bp}$; it is well known that fragments of this length are very difficult to amplify when the original tissue is FFPET. In fact this constitutes a great achievement of this protocol. Although other authors (Fang et al., 2002) already reported a new FFPET gDNA extraction method that allows the amplification of single copy fragments with more than $1000 \mathrm{bp}$, this was tested only in a small number of samples (i.e. eight) without posterior analyses of sequences. Moreover, there has been a lack of subsequent published interest in it (Gilbert et al., 2007a). With our protocol for DNA extraction from FFPET it was possible to obtain DNA from all thirty six samples and in twenty two of them we successfully amplified and sequenced a fragment of $1182 \mathrm{bp}$. Furthermore, DNA fragments with 590 bp (cf. Table 2) were amplified with even better success and also sequenced. Recent studies revealed lowest percentage of amplification for fragments around $600 \mathrm{bp}$ : in thirteen samples tested Talaulikar et al. (2008) achieved 10\% of amplification and Gillio-Tos et al. (2007) were able to amplify 5\% of 365 gDNA samples tested.

As far as we know, this is the first report where it was possible to PCR amplify so many samples from FFPET, with DNA fragments length from $201 \mathrm{bp}$ to $1182 \mathrm{bp}$ of single copy genes, and where the sequencing of the PCR products was accomplished. Finally, in contrast to the previously work reported by different authors (Meehan et al., 2007) the analysis of single-nucleotide polymorphism (SNP) was possible to perform in larger DNA fragments (more than $590 \mathrm{bp}$ ) without previous treatment of the gDNA with, for instances, Bst DNA polymerase (unpublished data regarding SNP analysis).

In conclusion, the protocol presented here has great potential to be applied in different molecular studies that involved FFPET material.

\section{Acknowledgements}

This work was supported by the project POCI/CVT/62940/2004 and the $\mathrm{PhD}$ grant $\mathrm{SFRH} / \mathrm{BD} / 23406 / 2005$ of the Science and Technology Foundation (FCT) from Portugal. We are deeply grateful to Dr. Paulo Pimenta from the Trás-os-Montes Veterinary Hospital for providing the fresh cat mammary, skin and muscle samples.

\section{References}

Aviel-Ronen, S., Zhu, C.Q., Coe, B.P., Liu, N., Watson, S.K., Lam, W.L., Tsao, M.S., 2006. Large fragment Bst DNA polymerase for whole genome amplification of DNA from formalin-fixed paraffin-embedded tissues. BMC Genomics 7, 312.

Benavides, J., Garcia-Pariente, C., Gelmetti, D., Fuertes, M., Ferreras, M.C., GarcíaMarín, J.F., Pérez, V., 2006. Effects of fixative type and fixation time on the detection of Maedi Visna virus by PCR and immunohistochemistry in paraffinembedded ovine lung samples. Journal of Virological Methods 137, 317-324.

De Maria, R., Olivero, M., Iussich, S., Nakaichi, M., Murata, T., Biolatti, B., Di Renzo, M.F., 2005. Spontaneous feline mammary carcinoma is a model of HER2 overexpressing poor prognosis human breast cancer. Cancer Research 65, 907-912.

Dubeau, L., Chandler, L.A., Gralow, J.R., Nichols, P.W., Jones, P.A., 1986. Southern blot analysis of DNA extracted from formalin fixed pathology specimens. Cancer Research 46, 2964-2969.

Fang, S.G., Wan, Q.H., Fujihara, N., 2002. Formalin removal from archival tissues by Critical Point Drying. Biotechniques 33, 604-611.

Gilbert, M.T.P., Sanchez, J.J., Haselkorn, T., Jewell, L.D., Lucas, S.B., van Marck, E., Børsting, C., Morling, N., Worobey, M., 2007a. Multiplex PCR with minisequencing as an effective higher-throughput SNP typing method for formalin fixed tissue. Electrophoresis 28, 2361-2367.

Gilbert, M.T.P., Haselkorn, T., Bunce, M., Sanchez, J.J., Lucas, S.B., Jewell, L.D., van Marck, E., Worobey, M., 2007b. The isolation of nucleic acids from fixed, paraffinembedded tissues - which methods are useful when? PLoS ONE 2 (6), e537. doi:10.1371/journal.pone.0000537.

Gillio-Tos, A., De Marco, L., Fiano, V., Garcia-Bragado, F., Dikshit, R., Boffetta, P., Merletti, F., 2007. Efficient DNA extraction from 25-year-old paraffin-embedded tissues: study of 365 samples. Pathology $39,345-348$.

Gjerdrum, L.M., Sorensen, B.S., Kjeldsen, E., Sorensen, F.B., Nexo, E., Hamilton-Dutoit, S., 2004. Real-time quantitative PCR of microdissected paraffin-embedded breast carcinoma. An alternative method for HER-2/neu analysis. Journal of Molecular carcinoma. An altern
Diagnostics 6, 42-51.

Greer, C.E., Peterson, S.K., Kiviat, N.B., Manos, M.M., 1991. PCR amplification from paraffin-embedded tissues. Effects of fixative and fixation time. American Journal of Clinical Pathology 95, 117-124.

Hansen, K., Khanna, C., 2004. Spontaneous and genetically engineered animal models: use in preclinical cancer drug development. European Journal of Cancer 40, 858-880.

Jackson, D.P., Lewis, F.A., Taylor, G.R., Boylston, A.W., Quirke, P., 1990. Tissue extraction of DNA and RNA and analysis by the polymerase chain reaction. Journal of Clinical Pathology 43, 499-504.

Jacobs, S., Thompson, E.R., Nannya, Y., Yamamoto, G., Pillai, R., Ogawa, S., Bailey, D.K., Campbell, I.G., 2007. Genome-wide, high-resolution detection of copy number, loss of heterozygosity, and genotypes from formalin-fixed, paraffin-embedded tumor tissue using microarrays. Cancer Research 67, 2544-2551

Kidney, B.A., Haines, D.M., Ellis, J.A., Burnham, M.L., Jackson, M.L., 2002. Evaluation of formalin-fixed paraffin-embedded tissues from feline vaccine site-associated sarcomas for feline foamy virus DNA. American Journal of Veterinary Research 63, 60-63.

Leers, M.P.G., Schutte, B., Theunissen, P.H.M.H., Ramaekers, F.C.S., Nap, M., 1999. Heat pretreatment increases resolution in DNA flow cytometry of paraffin-embedded pretreatment increases resolution in
tumor tissue. Cytometry $35,260-266$.

MacEwen, E.G., 1990. Spontaneous tumors in dogs and cats: models for the study of cancer biology and treatment. Cancer and Metastasis Reviews9, 125-136.

Mayr, B., Reifinger, M., Alton, K., Schaffner, G., 1998. Novel p53 tumour suppressormutations in cases of spindle cell sarcoma, pleomorphic sarcoma and fibrosarcoma in cats. Journal Veterinary Research Communications 22, 249-255.

Meehan, M., Melvin, A., Gallagher, E., Smith, J., Mc Goldrick, A., Moss, C., Goossens, S., Harrison, M., Kay, E., Fitzpatrick, J., Dervan, P., Mc Cann, A., 2007. Alpha-TCatenin (CTNNA3) Displays tumour specific monoallelic expression in urothelial Catenin (CTNNA3) Displays tumour specific monoallelic expression
carcinoma of the bladder. Genes. Chromosomes and Cancer 46,587-593.

Miething, F., Hering, S., Hanschke, B., Dressler, J., 2006. Effect of fixation to the degradation of nuclear and mitochondrial DNA in different tissues. Journal of Histochemistry and Cytochemistry 54, 371-374.

Moller, K., Rinke, J., Ross, A., Buddle, G., Brimacombe, R., 1977. The use of formaldehyde in RNA-protein cross-linking studies with ribosomal subunits from Escherichia coli. European Journal of Biochemistry 76, 175-187.

Morris, J.S., Nixon, C., Bruck, A., Nasir, L., Morgan, I.M., Philbey, A.W., 2008.

Immunohistochemical expression of TopBP1 in feline mammary neoplasia in relation to histological grade, Ki67, ERa and p53. The Veterinary Journal 175,

218-226.

Murakami, Y., Tateyama, S., Rungsipipat, A., Uchida, K., Yamaguchi, R., 2000.

Immunohistochemical analysis of cyclin A, cyclin D1 and p53 in mammary tumors, squamous cell carcinomas and basal cell tumors of dogs and cats. Journal of Veterinary Medical Science 62, 743-750.

Nasir, L., Krasner, H., Argyle, D.J., Williams, A., 2000. Immunocytochemical analysis of 
the tumour suppressor protein (p53) in feline neoplasia. Cancer Letters 155,1-7.

Oosting, J., Lips, E.H., van Eijk, R., Eilers, P.H.C., Szuhai, K., Wijmenga, C., Morreau, H., van Wezel, T., 2007. High-resolution copy number analysis of paraffin- embedded archival tissue using SNP Bead Arrays. Genome Research 17, 368-376.

Poljak, M., Seme, K., Gale, N., 2000 RapidExtraction of DNA From Archival Clinical Specimens: Our Experiences. Pflügers Archiv 439, R42-R44. Review.

Ribeiro, C.N.M., Peres, L.C., Pina-Neto, J.M., 2004. DNA extraction and quantification from touch and scrape preparations obtained from autopsy liver cells. Brazilian Journal of Medical and Biological Research 37, 635-642.

Rogers, B.B., Alpert, L.C., Hine, E.A.S., Buffone, G.J., 1990. Analysis of DNA in fresh and fixed tissue by the polymerase chain reaction. American Journal of Pathology 136, $541-548$

Romero, R., Juston, A.C., Ballantyne, J., Henry, B.E., 1997. The applicability of formalinfixed and formalin-fixed paraffin embedded tissues in forensic DNA analysis. Journal of Forensic Sciences 42, 708-714.

Seixas, F., Pires, M.A., Lopes, C.A., 2008. Complex carcinomas of the mammary gland in cats: pathological and immunohistochemical features. The Veterinary Journal 176, $210-215$

Shi, S.R., Datar, R., Liu, C., Wu, L., Zhang, Z., Cote, R.J., Taylor, C.R., 2004. DNA extraction from archival formalin-fixed, paraffin-embedded tissues: heat-induced retrieval in alkaline solution. Histochemistry and Cell Biology 122, 211-218.

Stanta, G., Schneider, C., 1991. RNA extracted from paraffin-embedded human tissues is amenable to analysis by PCR amplification. Biotechniques 11,304-308.

Talaulikar, D., Gray, J.X., Shadbolt, B., McNiven, M., 2008. A comparative study of the quality of DNA obtained from fresh frozen and formalin-fixed decalcified paraffinembedded bone marrow trephine biopsies using two different methods. Journal of Clinical Pathology 61, 119-123.

Vail, D.M., MacEwen, E.G., 2000. Spontaneously occurring tumors of companion animals as models for human cancer. Cancer Investigation 18, 781-792.

Vékony, H., Ylstra, B., Wilting, S.M., Meijer, G.A., van de Wiel, M.A., Leemans, C.R., van der Waal, I., Bloemena, E., 2007. DNA Copy number gains at loci of growth factors and their receptors in salivary gland adenoid cystic carcinoma. Human Cancer Biology 13, 3133-3139.

Wang, L.T., Smith, A., Iacopetta, B., JWood, D., Papadimitriou, J.M., Zheng, M.H., 1996.

Nested PCR-SSCP assay for the detection of p53 mutations in paraffin wax embedded bone tumours: improvement of sensitivity and fidelity. Journal of Clinical Pathology: Molecular Pathology 49, M176-M178.

Winston, J., Craft, D.M., Scase, T.J., Bergman, P.J., 2005. Immunohistochemical detection of HER-2/neu expression in spontaneous feline mammary tumours. Veterinary and Comparative Oncology 3, 8-15.

Wu, L., Patten, N., Yamashiro, C.T., Chui, B., 2002. Extraction and amplification of DNA from formalin-fixed, paraffin-embedded tissues. Applied Immunohistochemistry and Molecular Morphology 10, 269-274.

Zappulli, V., De Zan, G., Cardazzo, B., Bargelloni, L., Castagnaro, M., 2005. Feline mammary tumours in comparative oncology. Journal of Dairy Research 72, 98-106.

Zsikla, V., Baumann, M., Cathomas, G., 2004. Effect of buffered formalin on amplification of DNA from paraffin wax embedded small biopsies using real-time PCR. Journal of Clinical Pathology 57, 654-656. 


\section{Table 1}

Analysis of the concentrations of the gDNA extracted from FFPET tissues

\begin{tabular}{|c|c|c|}
\hline $\begin{array}{c}\text { Concentrations of } \\
\text { the gDNA extracted }\end{array}$ & $\begin{array}{c}\text { Protocol without elimination } \\
\text { of the residual paraffin -A- }\end{array}$ & $\begin{array}{c}\text { Protocol with elimination of } \\
\text { the residual paraffin -B- }\end{array}$ \\
\hline Variable & ng/ll & ng/ll \\
\hline Mean & 166.1 & 262.6 \\
\hline Maximum & 529.7 & 696.2 \\
\hline Median & 145.2 & 223.5 \\
\hline Minimum & 15.9 & 37.2 \\
\hline
\end{tabular}

A-without elimination of the residual paraffin; B- with elimination of the residual paraffin. Comparison of variance between independent samples (Kruskal-Wallis pairwise comparisons) (A B): P (probability) $=0.0008$ (Significant).

\section{Table2}

The percentage of PCR amplification was calculated taking into account all the amplification experiments performed with the respective sets of primers (six different sets of primers were used) with thirty six gDNA samples obtained from FFPET

\begin{tabular}{|c|c|c|c|c|}
\hline Primer Set & $\begin{array}{c}\text { Fragment size } \\
(\mathrm{bp})\end{array}$ & $\begin{array}{c}\text { No FFPET } \\
\text { tested }\end{array}$ & $\begin{array}{c}\text { \% PCR } \\
\text { Amplification }\end{array}$ & $\begin{array}{c}\text { \% Sequencing } \\
\text { efficiency }\end{array}$ \\
\hline ERBB2-A & 343 & 36 & 67 & 100 \\
\hline ERBB2-B & 1182 & 36 & 60 & 100 \\
\hline p53-A & 355 & 36 & 97 & 100 \\
\hline p53-B & 590 & 36 & 97 & 100 \\
\hline Twist1-A & 201 & 36 & 100 & 100 \\
\hline Twist1-B & 316 & 36 & 100 & 100 \\
\hline
\end{tabular}



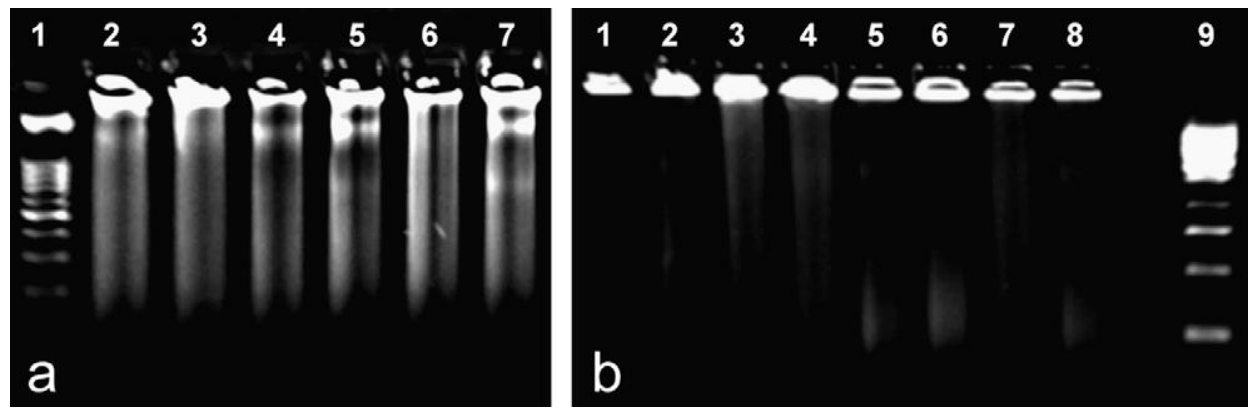

Fig. 1. Electrophoresis of $5 \mathrm{ll}$ (corresponding to 1000-2500 ng) of gDNA from FFPET in a 1\% agarose gel. gDNA extractions without (fig. a) and with (fig. b) the inclusion of an additional step to remove the paraffin. Lines 1 and 9 respectively in figures a and b: MassRuler DNA ladder (Fermentas Life Science).

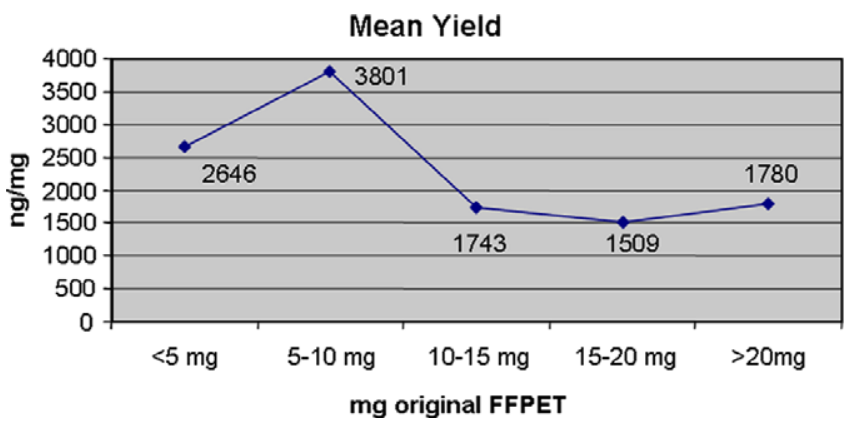

Fig. 2. Total DNA yields were analysed in five classes with respect to the FFPET input amount (weight in $\mathrm{mg}$ ). The data was obtained with the formula: ng DNA/mg FFPET $=$ [mean DNA concentration from various samples (ng/ll) sample volume (ll)] / FFPET weight (mg).

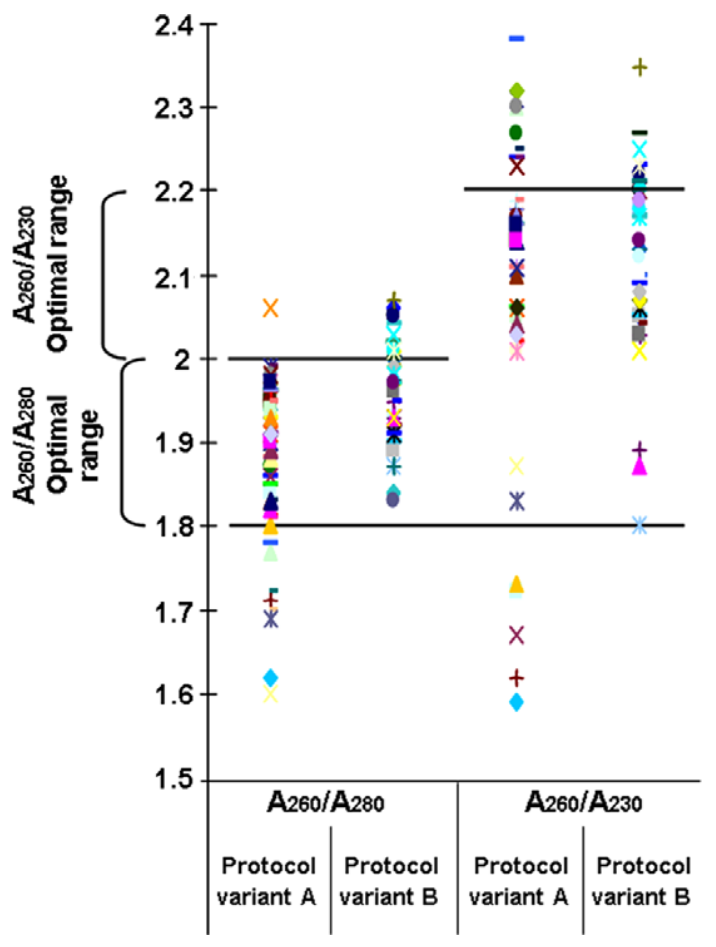

Fig. 3. Analysis of the quality of the gDNA samples by NanoDrop ND-1000. Distribution of the ratio values, A260/A280 and A260/A230, for all samples analysed. 


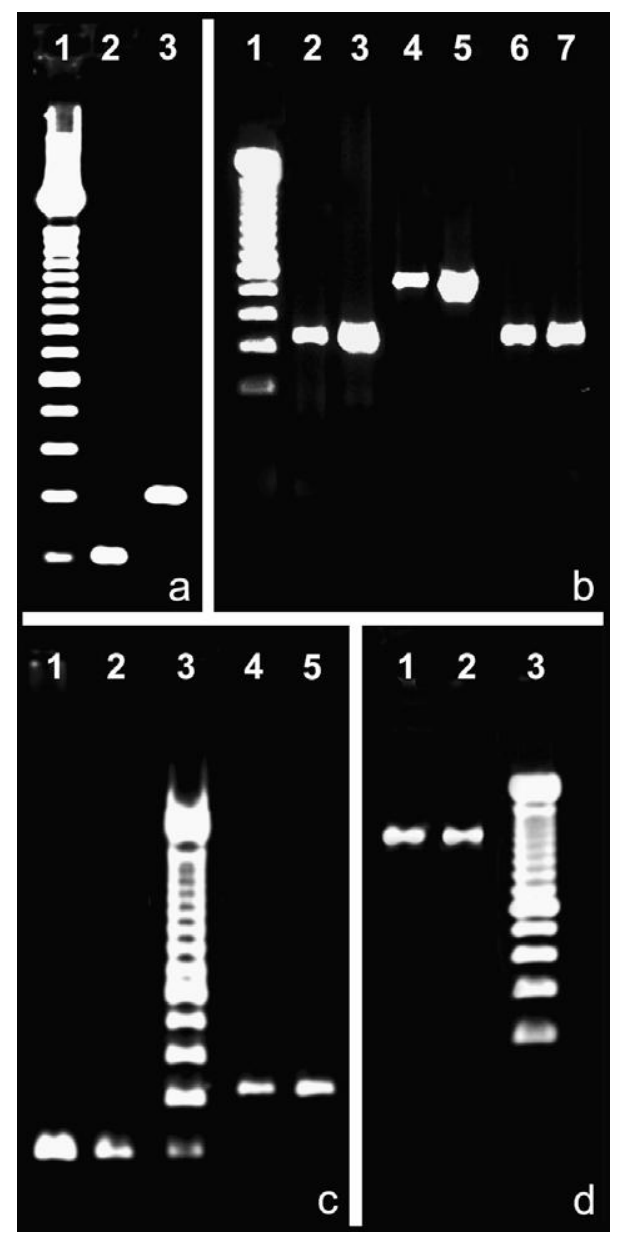

Fig. 4. Examples of the DNA fragment amplification using gDNA samples obtained from frozen material (a) and FFPET (b-d). Amplicons from Twist1 - 201bp (fig. a, line2 and fig. c, lines 1-2) and 316 bp (fig. a, line 3 and fig. c, lines 4-5); ERBB2- 343 bp (fig. b, lines 2-3) and 1182 bp (fig. d, lines 1-2); p53 - 355bp (fig. b, lines 6-7) and590 bp (fig. b, lines 4-5). DNA ladder of 100 bp (Invitrogen Life Technology) in line 1 (Fig a and b) and line 3 (Fig c and d). 